\title{
Theorizing a More Complete Picture: Integrating Interpersonal Communication with Computer-Mediated Communication
}

Andrew High

Penn State University

As the title of this journal makes explicit, taking the study of human communication and technology seriously requires a sophisticated consideration of both human communication and technology. Scholars in psychology, sociology, computer science, and media studies produce interesting lines of research on communication technology; however, researchers who study interpersonal interactions have a firm understanding of the process of communication, including its message-based and relational dynamics. How people interact, communicate, and relate transcends differences in channels. Rather than focusing explicitly on technology, which changes over time due to both technological advancements and social whimsy, research on social interactions and myriad interpersonal processes is well-suited to advance research on technologically-mediated communication. In a world of rapidly changing technology, communication is constant.

Modern relationships utilize a variety of channels throughout the day to both enact novel behaviors and perform traditional behaviors in new ways (Caughlin, Basinger, \& Sharabi, 2013; Sundar, Jia, Waddell, \& Huang, 2015). Unfortunately, theorizing on the integration of human communication and technology has occurred in a piecemeal fashion. Despite a wealth of research that studies interpersonal and social interactions online, there are few models or theories that embrace the richness in both human communication and technology. There exists, then, a need to synthesize research on interpersonal communication and technology to provide a more complete understanding of how, when, and why technology changes processes and outcomes of interpersonal communication. Human Communication $\mathcal{E}$ Technology can be a place that welcomes that research

\section{Hinting at a Connection between Human Communication and Technology}

In recognizing the complexities of supportive interactions, Burleson (2009) asserted that the outcomes of these interactions are based on aspects of the sender of a message, the receiver of a message, the message itself, and the context of the interaction. He continued to note that "it appears that many (and perhaps most) of these factors operate in concert with each another - combining, qualifying, and moderating each other's influence" (p. 27). Although Burleson focused on supportive interactions, his observation holds for most interpersonal exchanges. The 
channel in which an interaction occurs is one aspect of context that shapes interactions, and researchers who embrace the complexity of technology alongside the richness of interpersonal communication are likely to produce the most sophisticated understanding of these interactions. Despite Burleson's (2009) emphasis on context, how technology or channels of communication shape the behaviors, relationships, or processes that constitute supportive exchanges is rarely considered in theorizing on interpersonal or supportive communication.

From the perspective of communication technology, Walther's (1996) hyperpersonal model asserts that communicators who interact online can sometimes achieve more effective interactions than they are able to experience in face-to-face contexts. In particular, factors related to message senders, receivers, communication channels, and feedback loops are all theorized contribute to potentially more effective interactions online than face-to-face. The hyperpersonal model acknowledges that senders can communicate better messages online, but a serious consideration of the message characteristics or relationship dynamics that promote hyperpersonal outcomes is outside the scope of that model. Like Burleson's (2009) comment above, Walther recognizes that communication is shaped by aspects of both communicators and the channels in which they interact. Burleson and Walther both recognized the multifaceted nature of communication, but they do so in different ways. Whereas Burleson focused on aspects of messages and relationships, Walther privileged the role of technology. With more and more researchers studying how interpersonal interactions occur online, future theorizing can include aspects of messages, relationships, and technologies within theories, rather than in separate theories.

Theories are likely to generate the most thorough explanations and posit the most accurate predictions when they integrate variations in messages and relational dynamics alongside features or affordances of technology. For example, research by Rains, Brunner, Akers, Pavlich, and Tsetsi (2016) explains how an integration of both interpersonal communication and technology can be leveraged to explain why outcomes of conversations differ between online and face-to-face interactions. People receiving supportive messages online report less worry and a greater decrease in uncertainty compared to people who interact face-to-face. Rains and colleagues combined theorizing about qualities of supportive messages with features of text-based CMC, including a lack of nonverbal cues, greater attentional resources, and more time to elaborate messages, to generate these predictions (Rains et al., 2016).

High and Solomon (2014) observed that common sex differences in supportive communication exist, albeit in slightly different ways when people interact online. Whereas men were able to produce more sensitive and effective supportive messages for both men and women when they interacted online compared to face-to-face, women evaluated insensitive messages they received from other women particularly negatively when the interactions occurred online versus faceto-face. Being able to predict why communication channels shape the production and evaluation of messages requires an understanding of not only supportive communication but also technology's influence on interactions. Anonymity and editability likely accounted for men's enhanced ability in online channels, whereas a reduction in nonverbal cues and emotional bandwidth were used to explain 
why women were particularly critical of ineffective messages online, based on women's greater efficacy as nonverbal communicators (High \& Solomon, 2014). Outside the context of supportive communication, scholars who study strategies of information seeking recognize that the capacity of online channels to gather and collect information offer new strategies for information seeking beyond the typical passive, active, and interactive strategies. Extractive information seeking utilizes "a vast storehouse of written comments generated by targets" that are archived by online sources (Ramirez, Walther, Burgoon, \& Sunnafrank, 2002, p. 220). The recognition of this unique form of information seeking was generated by a combination of interpersonal behaviors and technological capabilities.

As these examples illustrate, communication scientists are uniquely suited to push the study of technology forward, given their understanding of what occurs within relationships. Caughlin and Sharabi's (2013) communicative interdependence perspective observes that some couples experience difficulty transitioning between channels and that difficulty corresponds with detrimental outcomes. Understanding how people communicate within and across particular channels based on the features of those channels and their relationship provides a better understanding of when and why interacting within channels corresponds with certain outcomes. Previous research concludes that CMC facilitates a variety of difficult relational tasks, including rejecting dates (Walther \& Tong, 2011), expressing opinions about sensitive topics (Ho \& McLeod, 2008), revealing private information (Hales, 2009), apologizing (Coyne, Stockdale, Busby, Iverson, \& Grant, 2011), and "cooling off" during a conflict (Perry \& Werner-Wilson, 2011). Several of these findings have been attributed solely to differences between online and face-to-face interactions. Despite their entanglements, little theorizing synthesizes the nuance of messages and relationships with technology, and understanding how message and relational characteristics combine with aspects of technology can create deeper explanations and more precise predictions about human communication online.

\section{Looking Towards the Future}

If integrating theory on human communication and technology was simple, researchers would do so more frequently. How, then, should researchers build theories that consider aspects of both interpersonal interactions and technology with some degree of precision? The number of variables to consider in this theorizing is large, and as Burleson (2009) observed, many of these variables likely interact in complicated ways. One way to encompass the number of relevant variables is to follow the general structure of theories like advice response theory (ART; MacGeorge, Guntzviller, Hanasono, \& Feng, 2013). ART is a unique theory because it specifies categories of several variables as predictors, including variables related to source and message factors. More specifically, effective advice messages are theorized to include statements that emphasize the efficacy, feasibility, absence of limitations, and confirmation of a recipients' initial plans. Each of these individual message characteristics can combine with a number of source factors in interesting ways. In much the same way, theories of human communication online 
can categorize variables into the interpersonal and technological variables that are relevant to a given process. Then, researchers can articulate the specific communicative and technological variables that are thought to be influential. For example, a study that focuses on using technology to repair a relationship after a transgression can include a category of variables that describe interpersonal communication, including message dynamics, severity of a transgression, and relationship characteristics, alongside a category of variables related to technology, including efficacy in using certain channels, ability to transition between channels, and several affordances, to most thoroughly understand how aspects of the relationship and technology combine to influence outcomes. Such theorizing can perhaps most effectively capture elements of interpersonal communication with elements of technology that combine to predict perceptions, behaviors, and outcomes.

Research on human communication and technology can specify groups of variables related to messages and communication channels that likely shape relevant classes of outcomes. Researchers have identified numerous social affordances that shape CMC (Fox \& McEwan, 2016), and specific studies can argue for the relevance of certain affordances based on the goals of the study. Despite the enumeration of affordances, less research has connected specific features of channels to specific affordances. Taking this initial step would reduce the number of variables that needs to be considered in any given study. Both theorizing categories of variables and studying only the variables that are relevant for a given process can produce theory and research that models an interplay of messages, relationships, and communication channels.

Integrating the message and relational dynamics that are at the heart of scholarship on interpersonal communication with research on technology can push existing theories forward in interesting ways. Scholars can understand how theories of interpersonal communication are challenged or reworked when applied to new contexts or synthesized with research on technology. In so doing, researchers might find meaningful boundary conditions to theories of interpersonal communication. Anytime people communicate to accomplish social or relational goals online, their experiences are likely determined by aspects of the technology, their relationship, and the messages they communicate. Theorizing with this collection of variables in mind can create stronger theoretical arguments and expand the explanatory power of theories for contemporary relationships.

\section{References}

Burleson, B. R. (2009). Understanding the outcomes of supportive communication: A dual-process approach. Journal of Social and Personal Relationships, 26(1), 2138. doi: 10.1177/0265407509105519

Caughlin, J. P. \& Sharabi, L. L. (2013). A communicative interdependence perspective of close relationships: The connections between mediated and unmediated interactions matter. Journal of Communication, 63, 873-893. doi: 10.1111/ jcom.12046

Coyne, S. M., Stockdale, L., Busby, D., Iverson, B., \& Grant, D. M. (2011). “I luv u:)!": A descriptive study of the media use of individuals in romantic relationships. Family Relations, 60, 150-162. doi: 10.1111/j.1741-3729.2010.00639.x 
Fox, J., \& McEwan, B. (2017). Distinguishing technologies for social interaction: The perceived social affordances of communication channels scale. Communication Monographs, 84, 298-318. doi: 10.1080/03637751.2017.1332418

Hales, J. (2009). Are investors really willing to agree to disagree? An experimental investigation of how disagreement and attention to disagreement affect trading behavior. Organizational Behavior and Human Decision Processes, 108, 230241. doi: $10.1016 /$ j.obhdp.2008.08.003

High, A. C., \& Solomon, D. H. (2014). Communication channel, sex, and the immediate and longitudinal outcomes of verbal person-centered support. Communication Monographs, 81(4), 439-468. doi: 10.1080/03637751.2014.933245

Ho, S. S., \& McLeod, D. M. (2008). Social-psychological influences on opinion expression in face-to-face and computer-mediated communication. Communication Research, 35, 190-207. doi: 10.1177/0093650207313159

MacGeorge, E. L., Guntzviller, L. M., Hanasono, L. K., \& Feng, B. (2013). Advice response theory in interactions with friends. Communication Research, 211-231. doi: 10.1177/0093650213510938

Perry, M. S., \& Werner-Wilson, R. J. (2011). Couples and computer-mediated communication: A closer look at the affordances and use of the channel. Family and Consumer Sciences Research Journal, 40, 120-134. doi: 10.1111/j.15523934.2011.02099.x

Rains, S. A., Brunner, S. R., Akers, C., Pavlich, C. A., \& Tsetsi, E. (2016). The implications of computer-mediated communication (CMC) for social support message processing and outcomes: When and why Are the effects of support messages strengthened during CMC?. Human Communication Research, 42, 1-24. doi: 10.1111/hcre.12087

Ramirez, A., Walther, J. B., Burgoon, J. K., \& Sunnafrank, M. (2001). Information-seeking strategies, uncertainty, and computer-mediated communication: Toward a conceptual model. Human Communication Research, 28, 213-228. doi: 10.1111/j.1468-2958.2002.tb00804.x

Sundar, S., S., Jia, H., Waddell, T. F. \& Huang, Y. (2015). Toward a theory of interactive media effects (TIME): Four models for explaining how interface features affect user psychology. In S. Sundar (Ed.), The handbook of the psychology of communication technology (pp. 47-86). West Sussex, UK: John Wiley \& Sons, Inc.

Walther, J. B. (1996). Computer-mediated communication: Impersonal, interpersonal, and hyperpersonal. Communication Research, 23, 3-43. doi: 10.1177/009365096023001001

Walther, J. B., \& Tong, S. T. (2014) Inventing partners in computer-mediated communication: How CMC sustains self-fulfilling prophecies and relational attributions. In M. Gabriele (Ed.), Social computing and social media (pp. 517-527). Switzerland: Springer International Publishing. 